\title{
Influence of Sex-Mismatch on Prognosis After Heart Transplantation
}

\author{
Ana Ayesta* \\ Heart Area, Hospital Universitario Central de Asturias, Oviedo, Spain
}

The influence of donor and recipient sex on prognosis after heart transplantation has been analyzed in single, multi-center studies, and international registries. In most of them, sex-mismatch was identified as a risk factor for the worst prognosis, especially in men recipients of female heart. This could be attributed to physiological differences between women and men, differences in complications rates after heart transplantation (rejection, cardiovascular allograft vasculopathy, and primary graft failure), and pulmonary hypertension of the recipient. Confounding variables as age, urgent transplantation, and size-mismatch should also be considered. When allocating a graft, sex-mismatch should be considered but its influence in long-term survival should be further explored.

\section{OPEN ACCESS}

Edited by:

Emma Louise Robinson, University of Colorado, United States

Reviewed by:

Renata Cífková

Thomayer Hospital, Czechia Marie-José Goumans,

Leiden University Medical Center, Netherlands Steven Simmonds,

KU Leuven, Belgium

*Correspondence:

Ana Ayesta

ana.ayestalopez@gmail.com

Specialty section:

This article was submitted to Sex and Gender in Cardiovascular

Medicine,

a section of the journal

Frontiers in Cardiovascular Medicine

Received: 13 October 2020 Accepted: 16 February 2021

Published: 25 March 2021

Citation:

Ayesta A (2021) Influence of Sex-Mismatch on Prognosis After Heart Transplantation. Front. Cardiovasc. Med. 8:617062. doi: 10.3389/fcvm.2021.617062
Keywords: sex-mismatch, transplantation, prognosis, size-mismatch, rejection

\section{INTRODUCTION}

Heart failure (HF) is a clinical syndrome appearing in the final pathway of heart disease. It affects $1-2 \%$ of the adult population and it increases with age. The development of symptoms leads to morbidity, mortality, and poor quality of life. It has a poor prognosis, and heart transplantation (HT) is the treatment of choice in selected patients (1). When allocating a graft, donor, and recipient characteristics should be considered (2). Among them, the influence of donor/recipient sex-mismatch on prognosis has been broadly discussed. In this manuscript, we will address this issue and will try to figure out the mechanisms underlying this relationship.

\section{STATE OF THE ART: DONOR/RECIPIENT SEX-MISMATCH INFLUENCE ON HEART TRANSPLANTATION PROGNOSIS}

\section{Influence on Early and Long-Term Survival}

Initially, donor, and recipient sex influence on mortality were analyzed separately (3-9). After heterogeneous results, the influence of donor/recipient sex-mismatch was analyzed. In 1998 two studies found an influence on early mortality (10) and worst annual survival (11), due to lower survival in the female donor to male recipient (F/M) group, attributed to sizemismatch. Later, several studies confirmed this relation. In 2011, a single-center study with 857 patients did not show worse survival of F/M group compared to male donor to female recipient $(\mathrm{M} / \mathrm{F})$ group, although a trend in early mortality was suggested and better survival in recipients without mismatched heart was shown (12). Other studies reported significantly worst survival of F/M group in early stages after HT (13-15), while other authors related sex-mismatch with mortality regardless of the recipient sex $(10,16-18)$. However, in Bello et al. (16) sex matched pairing conferred a survival benefict, and $\mathrm{M} / \mathrm{F}$ combination had worst survival. On the contrary, others failed to relate sex-mismatch with poorer prognosis (19-24). In this sense, De Santo et al. (19) found no differences in one and three-year cumulative survival between sex-mismatch and sex-match patients in a cohort with 99 patients. 
Jalowiec et al. (20) found in a multicentric analysis of 347 patients no significant differences in early survival (30-days and 1-year survival) between sex-mismatch and sex-matched patients. Tsao et al. (21) and Yamani et al. (22) also did not find differences in survival between 4 groups created according to donor/recipient sex. In 2014, Correia et al. published the results of the analysis of 200 male recipients in a Portuguese center. They did not find higher mortality in sex-mismatch group than in sex-matched group. The authors reported selection bias, as recipients of mismatched hearts had lower pulmonary gradient and lower systolic pulmonary pressure (24). The results of the Spanish Heart Transplantation Registry published in 2014 included 4,625 patients and found an influence of sex-mismatch on early mortality only in male recipients and mainly in those with pulmonary gradient $>13 \mathrm{mmHg}(25)$.

The results of the analysis of large registries, expected to be more accurate and reliable, also reported heterogeneous results (26-32). In 2002, Zeier et al. (29) found higher mortality of F/M group analyzing the Collaborative Transplant Study database. The United Network for Organ Sharing (UNOS) database analysis published in 2009 (28) compared 4 groups, based on the combination of donor and recipient sex, and showed a lower survival at 5 years in the $\mathrm{F} / \mathrm{M}$ group and greater survival in the male to male $(\mathrm{M} / \mathrm{M})$ group. A later analysis of this same database (31) found that survival differences associated with sex-mismatch were modified by differences in predicted heart mass (PHM) by a mathematical model. In a retrospective analysis of 31,634 patients, the authors found that a difference of 10 to $15 \%$ in PHM (undersized heart) between donor and recipient resulted in higher risk. In fact, when adjusting by PHM, they showed higher mortality in M/F group. The results of the International Society for Heart and Lung Transplantation (ISHLT) have also been analyzed several times $(26,30,32)$. In 2012 (30) an increase in mortality in F/M was reported compared to $\mathrm{M} / \mathrm{M}$, influenced by early mortality. Later, Kackmarek et al. (26) analyzed 67,855 transplanted patients and found the worst annual survival rates in $\mathrm{F} / \mathrm{M}$ group. The most recent analysis included 52,455 patients (32) and found that sex-mismatch increased mortality independently of weight match. The results of the University of Alabama - Cardiac Transplant Research database (CTRD), previously published, had found an interaction between sex, weight mismatch, and survival, especially in F/M. However, these differences were not observed when the weight mismatch was minimum (27).

A meta-analysis addressing sex-mismatch influence on oneyear survival has been recently published (33). After an initial search, 556 articles were found, and 45 articles were selected for full-text assessment. Finally, only 10 articles were included for data extraction and quantitative synthesis. 76,175 patients were analyzed. In male recipients, sex-mismatch was related with increased one-year mortality (21.2 vs. $16.6 \%$; OR $=1.38,95 \%$ CI $1.31-1.44, p<0.001)$. On the contrary in female recipient sex-mismatch was not a risk factor for one-year mortality (18.2 vs. $18.6 \%$; $\mathrm{OR}=0.93,95 \% \mathrm{CI}=0.85-1.00, p=0.06)$. The main limitations of this meta-analysis are the strong influence of the largest registry included in the results (26), the inability to determine the real influence of confounding factors and to determine the influence of early complications on long-term survival. However, it is the first meta-analysis on this field with studies of low bias, and the population included is representative of the HT population.

\section{Influence on Rejection}

The influence of sex-mismatch on rejection is unclear. Differences in the endocrine and immune system could lead to different adaptations to sex-mismatched heart (34). Women have a greater immune response $(6,35,36)$ that leads to higher levels of immunoglobulins and autoimmune diseases (37) and are supposed to have higher rates of rejection $(6-9,38)$. In 1998, Prendergast et al. (11) found higher rates of acute rejection in recipients with a sex-mismatched heart, as also did Aliabadi et al. (23) in 2011. In 2012, Jalowiec et al. (20) reported higher rejection rates in $\mathrm{M} / \mathrm{F}$ as had been previously published (39) and related lower survival to higher steroids requirements in the early post-transplant period. Patel et al. (40) reported, in a group of 1,299 patients, higher antibody-mediated rejection in M/F, but a recently published study found a higher risk in female recipients regardless of sex-mismatch (41). On the contrary, Bryan et al. (42) reported lower rejection rates in recipients of male hearts, mainly due to lower rates of the $\mathrm{M} / \mathrm{M}$ group compared to the $\mathrm{F} / \mathrm{M}$ group.

\section{Influence on Cardiac Allograft Vasculopathy}

The influence of sex-mismatch on cardiac allograft vasculopathy (CAV) has also been studied with heterogeneous results. A higher risk of $\mathrm{CAV}$ in $\mathrm{F} / \mathrm{M}$ group was reported in different studies $(38,43)$. Whether these results were attributed to sex-mismatch, female donor or male recipient is not clear (44-46). Other studies showed this relationship regardless of the combination (23) or in the F/F group (22). Eifert et al. (13) failed in 2012 to show this relation. Immunological or size-mismatch could be the reason underlying this association $(38,43)$.

\section{Influence on Primary Graft Failure}

Primary graft failure (PGF) is an impairment of the transplanted heart that occurs in the first $24 \mathrm{~h}$ after transplantation (47). It is the main cause of death in the early post-transplant period with up to $22 \%$ mortality (48). In an analysis of the Spanish Registry of Cardiac Transplantation (25) an increase in mortality in F/M in the first 30 days was found, but PGF was related to female donors, as previously noted (49) but not with sex-mismatch. However, some studies found a relation of PGF with sex-mismatch in male recipients (50-52), although Young et al. (51) found this was particularly important when the size exceeded $30 \%$.

In Table 1 we present a summary of the main studies that show the influence of sex-mismatch on higher rates of mortality, rejection, $\mathrm{CAV}$, and $\mathrm{PGF}$.

\section{DISCUSSION}

Different analysis on sex-mismatch influence on prognosis have shown different results. Some of them found the worst survival in $\mathrm{F} / \mathrm{M}$ group $(11-15,25-29,33)$, while others did not. How 
TABLE 1 | Summary of the main studies showing the influence of sex-mismatch on higher rates of mortality, rejection, cardiovascular allograft vasculopathy, and primary graft failure.

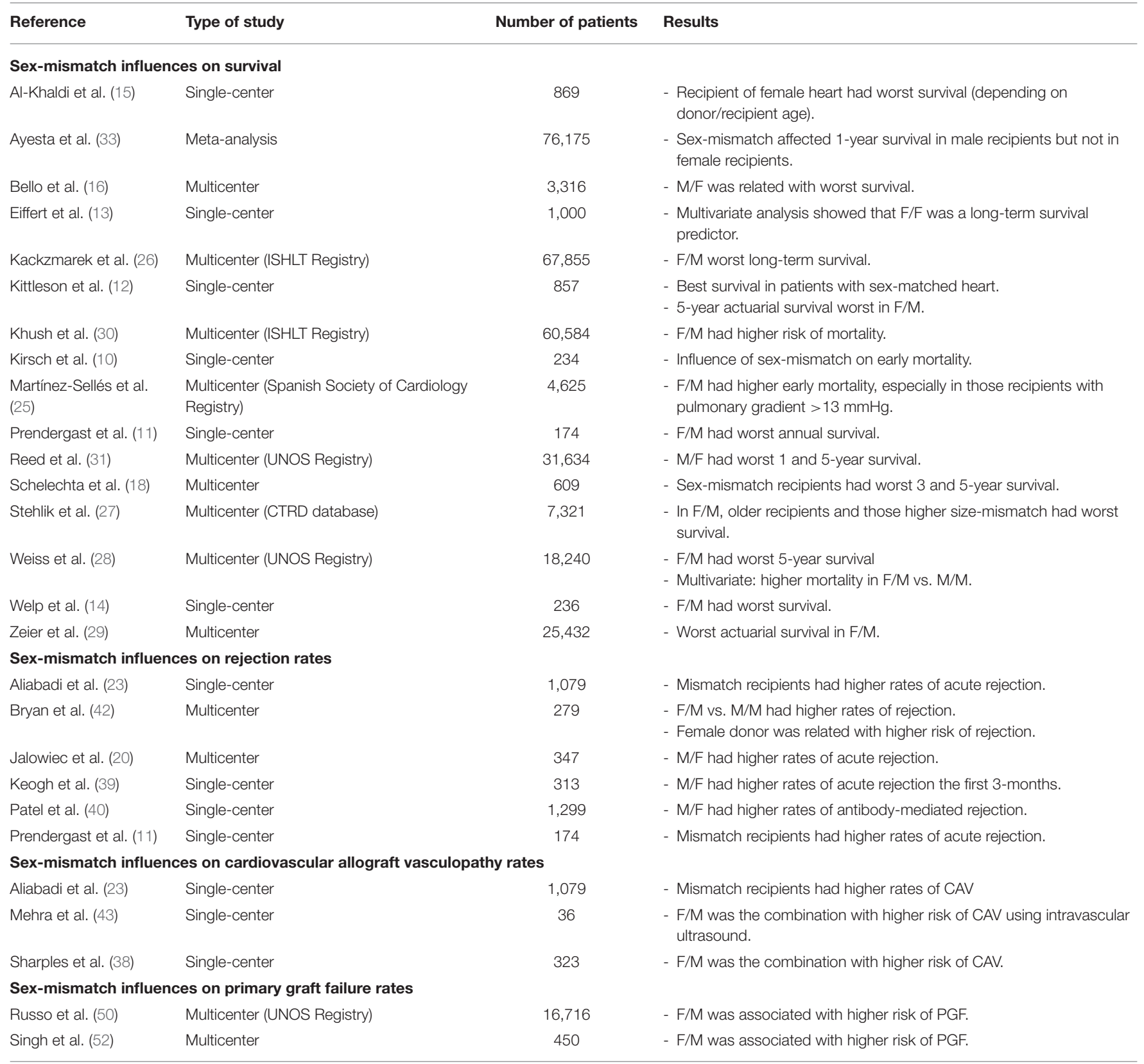

UNOS, United Network for Organ Sharing; CAV, Cardiac Allograft Vasculopathy; CTRD, Cardiac Transplant Research Database; F/F, female donor and female recipient group; F/M, female donor and male recipient group; ISHLT, International Society for Heart and Lung Transplantation; PGF, Primary Graft Failure; M/M, male donor and male recipient group; M/F, male donor and female recipient group.

sex-mismatch could influence on mortality is still unknown. Hypothetically, it could be due to anatomic, immune, hormone, and genetic differences between women and men. Also, differences in donor and recipient age and the emergency of the transplant could be involved. Most importantly, size-mismatch between donor and recipient and pulmonary hypertension of the recipient could be the main factors underlying this relationship and are currently being studied. The heterogeneous results in the influence on CAV and PGF are probably due to different definitions until consensus was reached.

\section{Anatomic and Physiological Differences}

Anatomic and functional differences between women and men's hearts lead to different abilities to adapt to different hemodynamic situations (53-56). Also, in transplanted women with previous male pregnancies, the presence of male cells 
could better explain the ability of women to adapt to a sexmismatched heart (57). On the contrary, differences in endocrine and immune system could increase rejection in women (3437). Advanced donor age is also related to mortality, mainly the first year after HT (58). In some studies, female donors older than male could be the reason under the worst survival of the F/M group (15, 18, 19, 24-26). However, some studies specifically addressed failed to show an interaction between age and sex-mismatch $(15,19,22,24-26)$. However, Al-Khaldi et al. (15) found an interaction between age and donor/recipient sex. Female recipients (younger) had no impact on multivariate analysis and the $\mathrm{M} / \mathrm{M}$ group was the one with the best one-year survival. This confirmed the previously published data from the UNOS registry that showed that recipient $<55$ years-old and donor $<30$ years-old had the best long-term survival (59).

\section{Urgent Transplant}

The analysis of the UNOS Registry published in 2009 (28) showed higher mortality in F/M only valid for those transplanted in maximum urgency. A previous analysis published in Spain (60) had also shown higher mortality in the $\mathrm{F} / \mathrm{M}$, due to the higher rates of urgent transplant.

\section{Undersizing Effect and Pulmonary Hypertension}

The most currently discussed reason underlying the relation between sex-mismatch and survival is the "under-sizing" effect. A smaller female heart would not be able to keep the cardiac output required by a man, resulting in immediate right ventricular failure (61). The use of different cardiac size measures has attempted to minimize the effect of sex-mismatch by reducing size-mismatch. However, it is still not clear that sex-mismatch influence on prognosis is totally due to size-mismatch.

An analysis of the Spanish Registry of Heart transplantation (25) showed that sex-mismatch increased mortality only in men with pulmonary hypertension the first month after HT. However, there were no significant differences in weight relationship between donor and recipient in $\mathrm{M} / \mathrm{M}$ vs. F/M. In the same way, the most recent analysis of ISHLT database (32) found that sex-mismatch increased mortality independently of weight match. They analyzed 52,455 transplants between 1994 and 2013 and defined three subgroups according to BMI: underweight, non-obese, and obese. Inappropriate weight match, defined as donor weight $<70 \%$ of the recipient's weight, was associated with 30-day mortality and cumulative mortality. F/M and M/F had higher rates of cumulative mortality compared with sexmatched patients but increased early mortality only in F/M. They found no interaction between inappropriate weight match and sex-mismatch, which would be expected if size differences were the main reason for increased mortality in this group. Previous analysis of the ISHLT database (26) had focused on donor and recipient body mass index (BMI). They suggested an "undersizing effect" due to F/M worse results after correction of weight and height and an "oversizing effect" with better short-term results in $\mathrm{M} / \mathrm{F}$, especially when the recipient had high pulmonary pressures. Other analysis of this same database (30) adjusted the results based on weight mismatch, using three different parameters: donor and recipient weight, donor and recipient weight difference, and weight ratio of the recipient regarding donor weight. They found worse survival in F/M, but they did not find an interaction of the difference in weight in this survival. UNOS data published in 2009 (28) studied BMI ratio and body surface area (BSA) ratio between donors and recipients, finding a quite precise adjustment, probably due to a deliberate move to allocate the graft adjusting by cardiac size. Other studies were consistent with this adjustment and showed no difference among the four groups in donor/recipient BSA ratio $(15,18,19)$.

However, a poor correlation between weight and heart size was shown, questioning the suitability of the measures used so far (31). Reed et al. (31) studied a new way of assessing this relationship with a mathematical formula. They conducted a retrospective study of 31,634 patients included in the UNOS registry, identifying undersizing pairs with increased risk. The formula calculated the PHM combining the predicted left ventricular and right ventricular cardiac mass. They found that a difference of $10-15 \%$ (undersized heart) resulted in a higher risk of mortality. In the adjusted analysis, the risk attributed to sex-mismatch in F/M disappeared and higher mortality was observed in M/F. These results would agree with the theory that cardiac size-mismatch is interacting with the worst survival in F/M. A most recent analysis of the UNOS registry $(19,168$ recipients between 2007 and 2016) assessed the ability of 5 size match metrics: PHM, weight, height, BMI, and BSA to predict 1-year mortality after HT (62). They found that PHM is the optimal donor-recipient size for the prediction of mortality. The increased mortality associated with donor-recipient PHM undersizing below 0.86 persisted after adjusting for other factors affecting mortality, including sex-mismatch (62). The authors analyzed the role of sex-mismatch and PHM in heart offer turndown from donor size/weight. Most of them were F/M and $17 \%$ of them would be acceptable using the PHM cut off. F/M did not have an increased risk of death. The thirty-sixth adult heart transplantation report of the ISHLT published in 2019 addressed this issue (63). The authors analyzed donor-recipient size match based on PHM. They found that most of donor-recipients with weight match $\leq 30 \%$ had an acceptable PHM of $<20$ to $>20 \%$, which may lead to an increase in the use of hearts. The Pearson correlation coefficient (R) for weight mismatch compared to PHM mismatch was moderate-strong. They also analyzed donorrecipient $\mathrm{PHM}$ match according to sex match. F/M tended to be undersized and M/F tended to be oversized. They concluded that differences in size matching may be a part of mortality differences seen in different sex-mismatch combinations. Donorrecipient size match by $\mathrm{PHM}$ was identified as a significant predictor of 1- and 5-year mortality after heart transplant (for both recipients of undersized and oversized donors). A recent analysis of the OPTN/UNOS Registry (64) analyzed 3,788 F/M from 2005 to 2018. They demonstrated that increasing donor BMI relative to recipient BMI up to 1.5 was associated with improved survival. They speculated that BMI difference may be useful as a surrogate for PHM difference (due to the complexity of PHM) and might help mitigate the impact of sex-mismatch in heart transplantation. 
In patients with pulmonary hypertension, it is common practice to oversize donor hearts to prevent post-operative right ventricular failure. A recently published studied analyzed patients in the UNOS Registry (65) with moderate pulmonary hypertension. They found no benefit to oversizing donors. The unadjusted 1-year mortality was significantly higher for F/M compared with $\mathrm{M} / \mathrm{M}$ but after propensity matching, there was no difference in mortality between female and male donors at 90 days and 1 year. However, a higher risk for 1-year mortality persisted among $\mathrm{M} / \mathrm{F}$ in comparison with $\mathrm{M} / \mathrm{M}$. Also, there might be an interaction between weight difference, age, and recipient sex. A previous analysis of the CTRD had found an interaction between weight difference, age, and recipient sex, with higher one-year mortality in F/M with an older organ (more than 40 years) and a 30\% weight difference (27). A single-center Portuguese study (24) showed the same survival in those patients with sex-mismatch due to a good selection of grafts based on cardiac size in those patients with high transpulmonary gradient. However, it is a single-center and small sample study so their results cannot be considered superior to those observed on large international bases.
The influence of donor/recipient sex-mismatch on survival after HT is still not clear and the reasons underlying are still under debate. Adjusting size-mismatch may help to improve results but there are still some other factors that should be clarified. Further studies, especially prospective ones, would be necessary to improve survival and allocate the best graft in this era with scarcity of organs.

\section{CONCLUSION}

The influence of sex-mismatch on prognosis after HT has been broadly studied. In brief, a worst survival of male recipients receiving female heart was noted. However, new evidence shows that the optimization of cardiac size match between donor and recipient with adequate measures could modify the effect of sexmismatch.

\section{AUTHOR CONTRIBUTIONS}

The author confirms being the sole contributor of this work and has approved it for publication.

\section{REFERENCES}

1. Ponikowski P, Voors AA, Anker SD, Bueno H, Cleland JG, Coats AJ, et al. 2016 ESC guidelines for the diagnosis treatment of acute chronic heart failure: the Task Force for the diagnosis treatment of acute chronic heart failure of the European Society of Cardiology (ESC). Developed with the special contribution of the Heart Failure Association (HFA) of the ESC. Eur J Heart Fail. (2016) 18:891. doi: 10.1002/ejhf.592

2. Copeland H, Awori Hayanga JW, Neyrinck A, Mc Donald P, Dellgren G, Bertolotti A, et al. Donor heart and lung procurement: a consensus statement. J Heart Lung Transplant. (2020) 39:501-17. doi: 10.1016/j.healun.2020.03.020

3. Fabbri A, Bryan AJ, Sharples LD, Dunning J, Caine N, Schofield P, et al. Influence of recipient and donor gender on outcome after heart transplantation. J Heart Lung Transplant. (1992) 11:701-7.

4. McCarthy JF, McCarthy PM, Massad MG, Cook DJ, Smedira NG, Kasirajan V, et al. Risk factors for death after heart transplantation: does a single-center experience correlate with multicenter registries? Ann Thorac Surg. (1998) 65:1574-8. doi: 10.1016/S0003-4975(98)00138-6

5. Tsai FC, Marelli D, Bresson J, Gjertson D, Kermani R, Ardehali A, et al. Recent trends in early outcome of adult patients after heart transplantation: a single-institution review of 251 transplants using standard donor organs. Am J Transplant. (2002) 2:539-45. doi: 10.1034/j.1600-6143.2002.20608.x

6. Crandall BG, Renlund DG, O'Connell JB, Burton NA, Jones KW, Gay WA, et al. Increased cardiac allograft rejection in female heart transplant recipients. J Heart Transplant. (1988) 7:419-23.

7. Esmore D, Keogh A, Spratt P, Jones B, Chang V. Heart transplantation in females. J Heart Lung Transplant. (1991) 10:335-41.

8. Kirklin JK, Naftel DC, Bourge RC, White-Williams C, Caulfield JB, Tarkka $\mathrm{MR}$, et al. Rejection after cardiac transplantation. A time-related risk factor analysis. Circulation. (1992) 86:II236-41.

9. Kobashigawa JA, Kirklin JK, Naftel DC, Bourge RC, Ventura HO, Mohanty $\mathrm{PK}$, et al. Pretransplantation risk factors for acute rejection after heart transplantation: a multiinstitutional study. The Transplant Cardiologists Research Database Group. J Heart Lung Transplant. (1993) 12:355-66.

10. Kirsch M, Baufreton C, Naftel DC, Benvenuti C, Loisance DY. Pretransplantation risk factors for death after heart transplantation: the Henri Mondor experience. J Heart Lung Transplant. (1998) 17:268-77.

11. Prendergast TW, Furukawa S, Beyer AJ III, Browne BJ, Eisen HJ, Jeevanandam V. The role of gender in heart transplantation. Ann Thorac Surg. (1998) 65:88-94. doi: 10.1016/S0003-4975(97)01105-3

12. Kittleson MM, Shemin R, Patel JK, Ardehali A, Kawano M, Davis S, et al. Donor-recipient sex mismatch portends poor 10-year outcomes in a single-center experience. J Heart Lung Transplant. (2011) 30:1018-22. doi: 10.1016/j.healun.2011.03.018

13. Eifert S, Kofler S, Nickel T, Horster S, Bigdeli AK, Beiras-Fernandez A, et al. Gender-based analysis of outcome after heart transplantation. Exp Clin Transplant. (2012) 10:368-74. doi: 10.6002/ect.2011.0164

14. Welp H, Spieker T, Erren M, Scheld HH, Baba HA, Stypmann J. Sex mismatch in heart transplantation is associated with increased number of severe rejection episodes and shorter long-term survival. Transplant Proc. (2009) 41:2579-84. doi: 10.1016/j.transproceed.2009.06.098

15. Al-Khaldi A, Oyer PE, Robbins RC. Outcome analysis of donor gender in heart transplantation. J Heart Lung Transplant. (2006) 25:461-8. doi: 10.1016/j.healun.2005.11.456

16. Bello RA, D'Alessandro DA, Maybaum S, Goldstein DJ. The impact of donor-recipient gender- matching on survival and rejection after cardiac transplantation. J Heart Lung Transplant. (2009) 28:S185. doi: 10.1016/j.healun.2008.11.353

17. Maltais S, Jaik NP, Feurer ID, Wigger MA, Disalvo TG, Schlendorf KH, et al. Mechanical circulatory support and heart transplantation: donor and recipient factors influencing graft survival. Ann Thorac Surg. (2013) 96:12528. doi: 10.1016/j.athoracsur.2013.05.043

18. Schlechta B, Kocher AA, Ofner P, Nourani F, Zimmerl M, Grimm M, et al. Impact of gender mismatch on the outcome of heart transplantation. Transplant Proc. (1999) 31:3340-2. doi: 10.1016/S0041-1345(99)00818-0

19. De Santo LS, Marra C, De FM, Amarelli C, Romano G, Cotrufo M. The impact of gender on heart transplantation outcomes: a single center experience. Ital Heart J. (2002) 3:419-23.

20. Jalowiec A, Grady KL, White-Williams C. First-year clinical outcomes in gender-mismatched heart transplant recipients. J Cardiovasc Nurs. (2012) 27:519-27. doi: 10.1097/JCN.0b013e31822ce6c9

21. Tsao CI, Chen RJ, Chou NK, Ko WJ, Chi NH, Yu HY, et al. The influence of gender on survival after heart transplantation. Transplant Proc. (2008) 40:2634-5. doi: 10.1016/j.transproceed.2008.08.025

22. Yamani MH, Erinc SK, McNeill A, Ratliff NB, Sendrey D, Zhou L, et al. The impact of donor gender on cardiac peri-transplantation ischemia injury. J Heart Lung Transplant. (2005) 24:1741-4. doi: 10.1016/j.healun.2005. 02.022

23. Aliabadi AZ, Dunkler D, Eskandary FA, Pelanek C, Haberl T, Sandner $\mathrm{S}$, et al. Do boys and girls match?- The effect of gender mismatch 
in cardiac transplantation. J Heart Lung Transplant. (2011) 30:S194. doi: 10.1016/j.healun.2011.01.591

24. Correia P, Prieto D, Batista M, Antunes MJ. Gender mismatch between donor and recipient is a factor of morbidity but does not condition survival after cardiac transplantation. Transpl Int. (2014) 27:1303-10. doi: 10.1111/tri.12432

25. Martinez-Selles M, Almenar L, Paniagua-Martin MJ, Segovia J, Delgado JF, Arizón JM, et al. Donor/recipient sex mismatch and survival after heart transplantation: only an issue in male recipients? An analysis of the Spanish Heart Transplantation Registry. Transpl Int. (2015) 28:305 doi: $10.1111 /$ tri. 12488

26. Kaczmarek I, Meiser B, Beiras-Fernandez A, Guethoff S, Uberfuhr P, Angele M, et al. Gender does matter: gender-specific outcome analysis of 67,855 heart transplants. Thorac Cardiovasc Surg. (2013) 61:29-36. doi: $10.1055 / \mathrm{s}-0032-1331467$

27. Stehlik J, Feldman DS, Brown RN, VanBakel AB, Russel SD, Ewald GA, et al. Interactions among donor characteristics influence post-transplant survival: a multi-institutional analysis. J Heart Lung Transplant. (2010) 29:291-8. doi: 10.1016/j.healun.2009.08.007

28. Weiss ES, Allen JG, Patel ND, Russell SD, Baumgartner WA, Shah AS, et al. The impact of donor-recipient sex matching on survival after orthotopic heart transplantation: analysis of 18000 transplants in the modern era. Circ Heart Fail. (2009) 2:401-8. doi: 10.1161/CIRCHEARTFAILURE.108.844183

29. Zeier M, Dohler B, Opelz G, Ritz E. The effect of donor gender on graft survival. J Am Soc Nephrol. (2002) 13:2570-6. doi: 10.1097/01.ASN.0000030078.74889.69

30. Khush KK, Kubo JT, Desai M. Influence of donor and recipient sex mismatch on heart transplant outcomes: analysis of the International Society for Heart and Lung Transplantation Registry. J Heart Lung Transplant. (2012) 31:45966. doi: 10.1016/j.healun.2012.02.005

31. Reed RM, Netzer G, Hunsicker L, Mitchell BD, Rajagopal D, Scharf $\mathrm{S}$, et al. Cardiac size and sex-matching in heart transplantation: size matters in matters of sex and the heart. JACC Heart Fail. (2014) 2:73-83. doi: 10.1016/j.jchf.2013.09.005

32. Bergenfeldt H, Stehlik J, Höglund P, Andersson B, Nilsson J. Donor recipient size matching and mortality in heart transplantation: influence of body mass index and gender. J Heart Lung Transplant. (2017) 36:940-47. doi: 10.1016/j.healun.2017.02.002

33. Ayesta A, Urrútia G, Madrid E, Vernooij RWM, Vicent L, Martínez-Sellés M. Sex-mismatch influence on survival after heart transplantation: a systematic review and meta-analysis of observational studies. Clin Transplant. (2019) 20:e13737 doi: $10.1111 /$ ctr.13737

34. Bird MD, Karavitis J, Kovacs EJ. Sex differences and estrogen modulation of the cellular immune response after injury. Cell Immunol. (2008) 252:57-67. doi: 10.1016/j.cellimm.2007.09.007

35. Katz MR, Barnhart GR, Szentpetery S, Rider S, Thompson JA, Hess M, et al. Are steroids essential for successful maintenance of immunosuppression in heart transplantation? J Heart Transplant. (1987) 6:293-7.

36. Renlund DG, O'Connell JB, Gilbert EM, Watson FS, Bristow MR. Feasibility of discontinuation of corticosteroid maintenance therapy in heart transplantation. J Heart Transplant. (1987) 6:71-8.

37. Csete M. Gender issues in transplantation. Anesth Analg. (2008) 107:232-38. doi: 10.1213/ane.0b013e318163feaf

38. Sharples LD, Caine N, Mullins P, Scott JP, Solis E, English TA, et al. Risk factor analysis for the major hazards following heart transplantation-rejection, infection, and coronary occlusive disease. Transplantation. (1991) 52:244-52. doi: 10.1097/00007890-199108000-00012

39. Keogh AM, Valantine HA, Hunt SA, Schroeder JS, Oyer PE. Increased rejection in gender-mismatched grafts: amelioration by triple therapy. J Heart Lung Transplant. (1991) 10:106-10.

40. Patel J, Kittleson MM, Kawano M, Goldstein Z, Rafiei M, Barry O, et al. Does gender mismatch increase the risk of antibody-mediated rejection (AMR) after heart transplantation? J Heart Lung Transplant. (2011) 30:S178. doi: 10.1016/j.healun.2011.01.539

41. Nguyen LS, Coutance G, Salem J, Ouldamar S, Lebreton G, Combes A, et al. Effect of recipient gender and donor-specific antibodies on antibody-mediated rejection after heart transplantation. Am J Transplant. (2019) 19:1160-7. doi: $10.1111 /$ ajt.15133
42. Bryan CF, Mitchell SI, Borkon AM, Curtis J, Demmy T, Estep TH, et al. Influence of donor gender on patient mortality after heart transplantation. Transplant Proc. (1996) 28:149-51.

43. Mehra MR, Ventura HO, Escobar A, Cassidy CA, Smart FW, Stapleton DD. Does donor and recipient sex influence the development of cardiac allograft vasculopathy? Transplant Proc. (1995) 27:1926-9.

44. Erinc K, Yamani MH, Starling RC, Young JB, Crowe T, Ratliff NB, et al The influence of donor gender on allograft vasculopathy: evidence from intravascular ultrasound. Transplant Proc. (2004) 36:3129-31. doi: 10.1016/j.transproceed.2004.10.072

45. Costanzo MR, Naftel DC, Pritzker MR, Heilman JK III, Boehmer JP, Brozena SC, et al. Heart transplant coronary artery disease detected by coronary angiography: a multiinstitutional study of preoperative donor and recipient risk factors. Cardiac Transplant Research Database. J Heart Lung Transplant. (1998) 17:744-53.

46. Caforio AL, Tona F, Fortina AB, Angelini A, Piaserico S, Gambino A, et al Immune and non-immune predictors of cardiac allograft vasculopathy onset and severity: multivariate risk factor analysis and role of immunosuppression. Am J Transplant. (2004) 4:962-70. doi: 10.1111/j.1600-6143.2004.00434.x

47. Kobashigawa J, Zuckermann A, Macdonald P, Leprince P, Esmailian F, Luu $\mathrm{M}$, et al. Report from a consensus conference on primary graft dysfunction after cardiac transplantation. J Heart Lung Transplant. (2014) 33:327-40. doi: 10.1016/j.healun.2014.02.027

48. Cosio Carmena MD, Gomez BM, Almenar L, Delgado JF, Arizon JM, Gonzalez VF, et al. Primary graft failure after heart transplantation: characteristics in a contemporary cohort and performance of the RADIAL risk score. I Heart Lung Transplant. (2013) 32:1187-95. doi: 10.1016/j.healun.2013.08.004

49. Hong KN, Iribarne A, Worku B, Takayama H, Gelijns AC, Naka Y, et al. Who is the high-risk recipient? Predicting mortality after heart transplant using pretransplant donor and recipient risk factors. Ann Thorac Surg. (2011) 92:520-7. doi: 10.1016/j.athoracsur.2011.02.086

50. Russo MJ, Iribarne A, Hong KN, Ramlawi B, Chen JM, Takayama H, et al. Factors associated with primary graft failure after heart transplantation. Transplantation. (2010) 90:444-50. doi: 10.1097/TP.0b013e3181e6f1eb

51. Young JB, Hauptman PJ, Naftel DC, Ewald G, Aaronson K, Dec GW, et al. Determinants of early graft failure following cardiac transplantation, a 10year, multi-institutional, multivariable analysis. J Heart Lung Transplant. (2001) 20:212. doi: 10.1016/S1053-2498(00)00460-5

52. Singh SSA, Banner NR, Rushton S, Simon AR, Berry C, Al-Attar N. ISHLT primary graft dysfunction incidence, risk factors, and outcome: a UK national study. Transplantation. (2019) 103:336-43. doi: 10.1097/TP.0000000000002220

53. Lorenz CH, Walker ES, Morgan VL, Klein SS, Graham TP Jr. Normal human right and left ventricular mass, systolic function, and gender differences by cine magnetic resonance imaging. J Cardiovasc Magn Reson. (1999) 1:7-21. doi: $10.3109 / 10976649909080829$

54. Marcus JT, DeWaal LK, Gotte MJ, Van der Geest RJ, Heethaar RM, Van Rossum AC. MRI-derived left ventricular function parameters and mass in healthy young adults: relation with gender and body size. Int J Card Imaging. (1999) 15:411-9. doi: 10.1023/A:1006268405585

55. Salton CJ, Chuang ML, O’Donnell CJ, Kupka MJ, Larson MG, Kissinger KV, et al. Gender differences and normal left ventricular anatomy in an adult population free of hypertension. A cardiovascular magnetic resonance study of the Framingham Heart Study Offspring cohort. J Am Coll Cardiol. (2002) 39:1055-60. doi: 10.1016/S0735-1097(02)01712-6

56. Martinez-Selles M, Munoa MD, Martinez E, Fernandez MA, Garcia E. The influence of sex on right ventricular dysfunction in patients with severely depressed left ventricular ejection fraction. Eur J Heart Fail. (2006) 8:400-3. doi: 10.1016/j.ejheart.2005.12.006

57. Bayes-Genis A, Bellosillo B, de la Calle O, Salido M, Roura S, Ristol FS, et al Identification of male cardiomyocytes of extracardiac origin in the hearts of women with male progeny: male fetal cell microchimerism of the heart. $J$ Heart Lung Transplant. (2005) 24:2179-83. doi: 10.1016/j.healun.2005.06.003

58. Lund LH, Edwards LB, Kucheryavaya AY, Dipchand AI, Benden C, Christie JD, et al. The registry of the international society for heart and lung transplantation: thirtieth official adult heart transplant 
report-2013; focus theme: age. J Heart Lung Transplant. (2013) 32:951-64. doi: 10.1016/j.healun.2013.08.006

59. Whitson BA, Ravi Y, Emani S, Lampert B, Kilic, Hasan A, et al. Heart transplant recipient and donor age mismatching: should the older recipient be paired with the older donor? J Heart Lung Transplant. (2014) 33:S163. doi: 10.1016/j.healun.2014.01.437

60. Izquierdo MT, Almenar L, Martinez-Dolz L, Moro J, Aguero J, Sanchez-Lazaro I, et al. Analysis of the impact of donor gender on early mortality. Transplant Proc. (2007) 39:2375-6. doi: 10.1016/j.transproceed.2007.07.059

61. Jeevanandam V, Furukawa S, Prendergast TW, Todd BA, Eisen HJ, McClurken JB. Standard criteria for an acceptable donor heart are restricting heart transplantation. Ann Thorac Surg. (1996) 62:1268-75. doi: 10.1016/0003-4975(96)00626-1

62. Kransdorf EP, Kittleson MM, Benck LR, Patel JK, Chung JS, Esmailian F, et al. Predicted heart mass is the optimal metric for size match in heart transplantation. J Heart Lung Transplant. (2019) 38:156-65. doi: 10.1016/j.healun.2018.09.017

63. Khush KK, Cherikh WS, Chambers DD, Harhay MO, Hayes D Jr, Hsich E, et al. The international thoracic organ transplant registry of the international society for heart and lung transplantation: thirtysixth adult heart transplantation report - 2019; focus theme: donor and recipient size match. J Heart Lung Transplant. (2019) 38:1056-66. doi: 10.1016/j.healun.2019.08.004

64. Barac YD, Jawitz OK, Hartwig MG, Klapper J, Schroder JN, Daneshmand MA, et al. Mitigating the impact of using female donor hearts in male recipients using BMI difference. Ann Thorac Surg. (2020). doi: 10.1016/j.athoracsur.2020.06.109. [Epub ahead of print].

65. Shah M, Saeed O, Shin J, Murthy S, Sims DB, Vukelic S, et al. Predicted heart mass-based size matching among recipients with moderate pulmonary hypertension: outcomes and sex effect. J Heart Lung Transplant. (2020) 39:648-56. doi: 10.1016/j.healun.2020.01.1339

Conflict of Interest: The author declares that the research was conducted in the absence of any commercial or financial relationships that could be construed as a potential conflict of interest.

Copyright $(02021$ Ayesta. This is an open-access article distributed under the terms of the Creative Commons Attribution License (CC BY). The use, distribution or reproduction in other forums is permitted, provided the original author(s) and the copyright owner(s) are credited and that the original publication in this journal is cited, in accordance with accepted academic practice. No use, distribution or reproduction is permitted which does not comply with these terms. 